\title{
Cultivation of College Students' Cross-Cultural Communicative Competence
}

\author{
Baohong Li, Fangfang Deng \\ Xi'an University of Technology, Shaanxi, China
}

Keywords: Cross-cultural Communication, The Third Place, College English Teaching.

Abstract. Cross-cultural communication has become one of the three major courses in college English teaching. In this paper, the authors review the cross-cultural communication in China and foreign countries, and then put forward some ways to cultivate the college students' cross-cultural communicative competence.

\section{Introduction}

In the important address of national conference on ideological and political work in colleges and universities, General Secretary Xi Jinping pointed out: we are in urgent need for higher education and scientific knowledge and outstanding talents. Higher foreign language education takes the responsibility of cultivating talents for opening up to the outside. Under the background of the implementation of "One Belt, One Road" strategy and the promotion of Chinese culture going abroad, our country has an increasingly strong desire for high-level foreign language talents and an increasingly urgent need to develop high-level professional foreign language education that meets the needs of the times. This provides a broad space for the reform and development of foreign language education in colleges and universities, and puts forward new requirements.

There is a big gap between the influence of Chinese culture to the outside and the international status of China, and the discourse system in the field of cross-cultural communication has long been dominated by some western developed countries. Therefore, China urgently needs to innovate foreign discourse system (Ye Hong, Wang Kefei, 2016). The newly issued 2016 edition of College English Curriculum Requirements clearly points out that college English courses shoulder the important task of opening up of the country to the outside, enhancing the international voice and cultivating international talents. The teaching objectives of college English include enhancing cross-cultural communication awareness and competence. Cross-cultural communication has become one of the three major courses in college English teaching.

In the era of "Internet Plus", the universality and mobility of the Internet enable people to access the Internet at any time and anywhere by means of smart phones, tablets and other smart terminals, which not only changes the way and means people acquire knowledge and information, but also changes the learning concepts and ways of foreign language learners. Knowledge closely links all nations and countries together. Cross-cultural communication between people with different cultural backgrounds has become a new way of learning in modern society.

In the field of cross-cultural communication in China, the research is slow. Some researchers believe that foreign language education itself is cross-cultural communication. The effective 
organization of foreign language teaching activities is a process of positive transfer of understanding and deepening cross-cultural awareness. (Chen Fang, 2016)

\section{Theory of "The Third Place"}

The concept of "the third place" in the field of cross-cultural communication and foreign language education was proposed by Professor Claire Kramsch of University of California, Berkeley in 1993. It refers to through cross-cultural exploration and negotiation a intermediate zone exists between native language culture and foreign language culture. Here, both native language and foreign culture can be strengthened and deepened, forming a new culture to allow communicators from different language and cultural backgrounds to communicate flexibly and freely. "The third place" is a kind of cultural innovation where native language culture and foreign language culture can achieve real equality, so that communicators can form cross-cultural composite personality to meet the increasing needs of political, economic and cultural exchanges in the modern world.

"The third place" of cross-cultural communication includes three aspects of cognition: cross-cultural identity, cultural interface and the third perspective. In college English class, the building of the third place system of cross-cultural communication can guide students to establish a cognitive system of cross-cultural communication from daily fragmented learning and communication in the Internet era, look at culture from all perspectives and get rights on the basis of mutual cooperation and mutual protection, at the same time learn to stick to the principles on the basis of cooperation to obtain corresponding voice of native culture.

\section{Problems of Teaching to be Solved}

As early as in 2007, the College English Curriculum Requirements put forward the contents of cross-cultural communication in the teaching objectives and requirements, but in reality, the curriculum construction of cross-cultural communicative competence for non-foreign language majors is far less than that of foreign language majors. What is more serious is that the public English classes have been cut in colleges and universities in recent years. In addition, the current cross-cultural teaching is still based on the traditional method of classroom teaching and follows the mode of combining the learning in and outside the classroom. It is difficult for students, especially non-foreign language majors, to ensure the acquisition of sufficient cultural knowledge, let alone the cultivation of cross-cultural communicative competence.

\section{Ways to Cultivate College Students' Cross-cultural Communicative Competence}

\subsection{Strengthening Cross-cultural Awareness}

The purpose of English curriculum standard is to make the process of language learning become a process for students to form positive attitude, active thinking and bold practice, improve cross-cultural awareness and form independent learning ability. The important task of higher education is to cultivate cross-cultural talents with international ideas, global consciousness, international communication ability and international competitiveness for scientific, technological and economic construction, and to cultivate international talents to be employed worldwide. Through the study of cross-cultural communication, students can realize their own culture, accept cultural differences, understand and respect different cultures in their own position, improve critical thinking, have knowledge, skills and value of cross-cultural communication, and understand the interpersonal relationship. The cultivation of students' cross-cultural awareness can not be effectively obtained by the traditional foreign language teaching of grammatical knowledge. According to students' cognitive ability, teachers should gradually expand the content and scope of 
cultural knowledge. The cultural knowledge of English-speaking countries in teaching should be closely related to students' daily life, knowledge structure and cognitive level, and should stimulate students' interest in learning English culture. It is necessary to expand students' exposure to foreign cultures, help them expand their vision, improve their sensitivity and ability to identify the similarities and differences between Chinese and foreign cultures, and lay a solid foundation for the further development of their cross-cultural communicative competence.

\subsection{Strengthening Major Construction}

In the major construction, it is necessary to further broaden the major, continue to strengthen the dominant discipline, transform and update traditional disciplines and majors, and eliminate the old and outdated curriculum content, adjust the major orientation, and form a comprehensive discipline and major structures that reflect the disciplinary advantages of the school and actively adapt to social development in accordance with the requirements of social development and the characteristics of the school. At the same time, strengthen close contact with the same industry, enterprises, and labor market, drive the modernization of major construction with informationization, promote the standardization of major construction with internationalization, improve the quality of education, and achieve the reform and innovation of talent cultivation mode.

\subsection{Reforming Curriculum Structure}

We should promote the internationalization of teaching content through the combination of reforming old curriculum and adding new curriculum, provide specialized international education courses, such as cross-cultural research, foreign language and culture, traditional Chinese culture in English and comparative research to cultivate students' international ideas and communication skills, introduce and enlarge the authentic teaching materials.

\subsection{Improving Teaching Quality}

Internationalization of foreign language teachers is the most basic condition for cultivating talents of cross-cultural communication. The teachers with international knowledge and experience can directly promote the development of teaching and scientific research in the direction of internationalization, so the colleges and universities should increase the number of teachers going abroad for further study in various forms, and select teachers to go abroad for further study, cooperative research, and learning and absorbing a large amount of new knowledge. In addition, inviting famous foreign scholars to give lectures is a powerful measure to improve the schooling level and enhance the popularity and internationalization degree of the school. The teachers with different cultural backgrounds get together to exchange ideas, which is helpful to the improvement of cross-cultural ability.

\subsection{Innovating Teaching Mode}

We can cultivate cross-cultural communicative competence with mobile intelligent terminals. In the era of "Internet+", the universality and mobility of the Internet enable people to access the Internet anytime and anywhere with smart phones, tablet computers and other intelligent terminals, which has changed the way and means of acquiring knowledge and information, as well as the methods of foreign language learners. Professor Wang Zhuli puts forward the concept of mobile learning, that is, learning with mobile terminal devices such as mobile phones anytime and anywhere. Its main characteristics are fragmentation and ubiquitous learning with mobile and wireless Internet anytime and anywhere. The mobile phone is increasingly favored by learners because of its powerful functions and convenient use among all kinds of mobile intelligent terminals. After the Internet learning in the 2.0 era (that is, the learning of moving the classroom to the Internet, including online open class, mooc, micro-class, flipped classroom and so on), Wang 
proposes the personalized online learning in 3.0 Internet+ era. With the development of digital smart campus, the wireless network is increasingly popular, and apps and high-quality learning resources in mobile phone is also widespread, many of which can be used for language and cross-cultural knowledge learning, such as QQ, WeChat, TED, iReader, NetEase Open Class, MOOC and other applications. In the digital campus, the mobile phone is an important tool for students to communicate and learn. In addition to watching teaching video resources, students can use mobile phones to discuss problems, complete assignments and examinations, which can be used to assist the cultivation of college students' cross-cultural communicative competence.

\subsection{Cultivating Innovation Spirit}

The innovative spirit is an important part of the cultivation of high-quality foreign language talents, so we should put innovative education reform in a more important position. We should pay more attention to teaching the new contents, the new progress of discipline research, the new experience of relevant research. In terms of teaching methods, we should pay more attention to interaction, encourage more discussion, interactive and personalized teaching, pay special attention to students' critical thinking and creative thinking, and examine students' ability to analyze and solve problems by using knowledge. In terms of teaching management, we should actively explore a more flexible student management system.

\section{Conclusion}

As the deepening of teaching reform of higher education institutions and networking of the teaching condition, we should apply various kinds of ways to improve the teaching of cross-cultural communication and the students' cross-cultural communicative competence. As foreign language teachers, by applying the theory of the third place, we should actively face the challenges in the new era, seize the opportunities, breakthrough the conventional ways, explore the new ways to cultivate the cross-cultural communicative competence of the college students, at last achieve the teaching goal of cultivating students' cross-cultural communicative competence.

\section{Acknowledgement}

This research was financially supported by the Shaanxi Provincial Social Science Fund Project (Program No. 2018M28), Education and Teaching Reform Project of Graduate School of Xi'an University of Technology (Program No. 252041806), Education and Teaching Reform Project of Xi'an University of Technology (Program No. xjy1939).

\section{References}

[1] Cheng Fang. Positive Transfer of General Education Concept on College Foreign Language Talents Cultivation [J]. Journal of Yanbian University (Social Science). 2016.7: 140-144.

[2] C. J. Kramsch. Context and culture in language teaching [M]. Oxford: Oxford University Press, 1993.

[3] College English Curriculum Requirements [M]. Ministry of Education of the People's Republic of China, 2016.

[4] Wang Zhuli. Why Are There "Digital Ruins" in the Network Education Resources [J]. Modern Distance Education Research. 2015.1: 46-53.

[5] Ye Hong, Wang Kefei. Exploration of The Third Place of Cross-cultural Transmission [J]. Seeker. 2016.5: 42-46. 